Tanya Martini, BROCK UNIVERSITY, tmartini@brocku.ca Ryan Verbey-Verutis, MAPLE LEAF EDUCATIONAL SYSTEMS, ryanverbeyverutis@mapleleafedu.com Jill Grose, BROCK UNIVERSITY, jgrose@brocku.ca Brad Clarke,BROCK UNIVERSITY, bclarke@brocku.ca Amy Elder, BROCK UNIVEERSITY, aelder@brocku.ca

\title{
Canadian Undergraduates' Reports of Co-curricular Involvement Across the Degree
}

\begin{abstract}
The study discussed in this article investigated university student beliefs and behaviours with respect to co-curricular activities among incoming $(n=983)$, mid-degree $(n=173)$, and graduating $(n=1006)$ students. When asked about their most significant learning experiences during their time at university, graduating students were more likely to report on co-curricular activities than those related to coursework. However, participation in co-curricular activities was not related to graduating students' feelings of preparedness to undertake a job search or apply for postgraduate education. Incoming students reported clear intentions to participate in some types of co-curricular activities (e.g., volunteering, intramural sports, clubs) but were more uncertain about others (e.g., events or activities related to global awareness, or diversity and inclusion). Parallel findings were observed with respect to actual co-curricular involvement among mid-degree and graduating students. This research is discussed in the context of university efforts to promote co-curricular activities to students in order to develop career ready transferrable skills, and the relevance of particular patterns of involvement to the current job market.
\end{abstract}

\section{KEYWORDS}

co-curricular, undergraduates, experiential, career preparation, transferrable skills

\section{CO-CURRICULAR INVOLVEMENT}

Research concerning the postsecondary experience has provided considerable evidence to support the importance of student engagement while completing an undergraduate diploma or degree (Bonet \& Walters, 2016; Kuh, Cruce, Shoup, Kinzie, \& Gonyea, 2008). While much of this literature is focused on engagement within the formal curriculum (i.e., in the context of for-credit courses), more recently researchers have also noted that student engagement in activities outside of courses may also be important or potentially more important than what is studied within courses or programs (Bass, 2012). Some institutions have dedicated resources to developing these out of the classroom experiences in a more formalized integrated way, referring to them as a co-curriculum. Elias (2014, p. viii) has defined the co-curriculum as consisting of 
university-affiliated activities that are outside the academic curricula, and provide opportunities for intentional learning and development. Types of activities that may be captured include: leadership opportunities (orientation, residence life, student clubs \& [sic] government, etc.), mentorship opportunities, community outreach and volunteerism, international experiences, athletics (intramural councils and varsity athletics), positions on formal boards and committees, and some student staff positions.

How does engagement in the co-curriculum benefit postsecondary students? Pascarella and Terenzini (2005) and Astin (1984) indicated that co-curricular involvement promotes a feeling of belonging at an institution, which is likely to have positive effects on student retention. Other potential benefits include feelings of institutional support, self-efficacy, academic achievement, and an understanding of others, as well as the development of practical skills such as networking strategies (Stirling \& Kerr, 2015). However, in addition to increasing feelings of connection to the institution (and, by extension, retention), co-curricular experiences may be important for at least two other reasons.

First, there is evidence to suggest that important learning outcomes can be fostered through participation in co-curricular activities (Bass, 2012). For example, they may help students to develop career-relevant skills, such as communication, critical thinking, teamwork, and leadership. Employers place considerable value on these and other "soft skills," and students who can effectively leverage their co-curricular involvement to demonstrate mastery of these skills may find themselves better positioned to secure meaningful employment upon graduation (Elias, 2014).

Second, co-curricular experiences may provide evidence of work experience that is increasingly seen as important by employers seeking to fill entry-level positions (Borwein, 2014a). As evidence of this trend, a content analysis of 316 Canadian entry-level job ads indicated that less than one quarter of employers were willing to consider applicants with no job experience. Indeed, on average these job ads indicated that employers were looking for approximately 1.5 to 2 years of experience from new employees (Borwein, 2014b). Some co-curricular experiences may help to provide this type of "on-thejob" experience that employers are demanding of new graduates. Community-based volunteer experiences and student staff positions, in particular, can be cited to address the work experience requirements outlined in job ads for entry-level positions, and Elias's (2014) survey of employers suggests that they are interested in learning about these types of experiences from job applicants.

Students are well aware of the potential employment value that is associated with co-curricular participation (Thompson, Clark, Walker, \& Whyatt, 2013). For example, a study by Roulin and Bangerter (2013) found 94 percent of their undergraduate participants were engaged in co-curricular activities, and 62 percent were involved in more than one activity. Results further demonstrated that much of the motivation for engaging in co-curricular activities stemmed from a desire to demonstrate that they possess the skills and competencies that employers look for. To date, however, researchers have not directly tested the correlation between co-curricular involvement and feelings of preparedness to undertake a job search or apply for postgraduate education. In our study, we examined this relationship in a large sample of graduating students.

Recognizing the advantages that are conferred by co-curricular involvement, Canadian postsecondary institutions are increasingly working toward helping students find such experiences and learn from their co-curricular participation (Bass, 2012). One method of doing so has been the 
implementation of institutional portals to assist students in finding co-curricular experiences that are in keeping with their interests; another is the creation of co-curricular records that allow students to document the learning that occurs through these experiences.

\section{Context of the study}

The study outlined in this paper is phase one of a longitudinal study examining students' engagement with a university co-curriculum and their perception of and ability to articulate the transferrable skills developed as part of their involvement. We have also begun to assess the impact of the co-curriculum in terms of its ability to help students make connections between the co-curriculum and their academic learning.

The first step involved the creation of an online engagement portal from which students can learn about events and opportunities that are happening on and off campus. Inside this engagement portal is the framework for an integrated co-curriculum - an interactive roadmap designed to help students develop skills and foster understanding with regard to 10 different co-curricular domains: arts and culture, community engagement, diversity and inclusion, global awareness, health and wellness, innovation, leadership and teamwork, personal growth, career development, and university spirit. Following an extensive consultation process, these domains were created because they offer the potential to develop the skills that employers increasingly expect from university graduates; others offer opportunities to enhance students' personal growth and help them make the most of their time at university. Students can simply use the portal to find co-curricular opportunities, or they can have each of their activities documented within the corresponding domain of the co-curriculum. Completion of each domain also requires that students complete a reflection about their learning. We believe that students who participate in a large number of the domains will have a richer, more meaningful postsecondary experience and will be better positioned to pursue a career or further education when they graduate.

\section{The study}

The study addressed three key issues in an effort to advance extant literature concerning student perceptions of co-curricular involvement. First, we investigated how curricular and co-curricular experiences compare in terms of graduating students' perceptions of their ability to foster important learning. Specific questions included Do students consider co-curricular experiences to be important? If so, what specific types of co-curricular experiences are identified as being particularly valuable? With respect to this question, we expected to replicate the reports of other researchers (e.g., Bass, 2012) who have indicated that co-curricular experiences are perceived as valuable, and that those noted as being particularly influential will include a number of the high-impact practices described by Kuh (2009) (e.g., service-learning experiences, international opportunities, and internships). However, the present research goes one step further and examines, in an exploratory manner, the extent to which students report that their most significant learning experiences come from the co-curriculum, as opposed to the formal curriculum.

Second, we were interested in examining the commonly held premise that participation in the co-curriculum helps students to feel better prepared for the job market, or other "next steps" (e.g., additional postsecondary training). To this end, we tested the hypothesis that the total amount of co- 
curricular involvement at graduation would be positively associated with perceptions of readiness to move on to a job search or further education.

Third, the current research examined co-curricular involvement from a developmental perspective. In particular, we were interested in examining the following questions: What co-curricular experiences do incoming students indicate that they intend to get involved in? What is the nature of the co-curricular experiences that mid-degree and graduating students report having actually engaged in? Owing to a dearth of literature related to this issue, these questions were investigated in an exploratory manner and no hypotheses were tested.

\section{METHOD}

\section{Participants}

Data for this phase of the study were collected from three samples. The first came from nine convocation ceremonies, during which we surveyed graduating students about their co-curricular involvement while completing their degree. One thousand and six students were recruited from the pool of university undergraduates who attended the spring convocations for the faculties of humanities ( $n=113 / 260$ attending; 43 percent response), education ( $n=152 / 465$ attending; 33 percent response), social sciences ( $n=292 / 557$ attending; 52 percent response), applied health and math and science ( $n=289 / 562$ attending; 51 percent response), and business ( $n=160 / 352$ attending; 45 percent response). In total, then, we recruited 1,006 out of 2,196 (46 percent) students attending the nine convocation ceremonies. Among this group, 325 participants identified as male, 617 identified as female, and 52 identified as other ( 12 participants did not supply an answer).

The second sample included undergraduate students who were approximately midway through their degree. These students were surveyed about their co-curricular involvement up to the date of the survey. Surveys $(n=1077)$ were sent out electronically to students who were in the middle of either a three-year (6-9 credits completed out of 15 required) or four-year degree (8-12 credits completed out of 20 required). The sample of students selected was stratified in such a way that five of the six faculties were represented in proportion to student enrolment figures (the Faculty of Education was not surveyed owing to a very small sample size). Students who received an invitation to participate were sent a reminder after 7 days, and the survey was closed after a total of 14 days. Of the surveys sent out, 173 were completed (response rate $=16$ percent). No data related to gender were gathered from this sample.

The third sample comprised incoming students who participated in day-long summer orientation sessions $(\mathrm{n}=986)$. These students were surveyed about their intention to participate in cocurricular activities during their degree. These data were gathered during a mandatory afternoon information session aimed at educating incoming students about the experience portal and the integrated co-curriculum; thus the participation rate was 100 percent. No data related to gender were gathered from this sample.

The data gathered from these three samples represent the first wave of data collection in a longterm study of co-curricular involvement. Eventually, the intention is to follow up with the incoming students as they approach the mid-point of their degree and again when they graduate. This data collection strategy will eventually allow us to contrast the cross-sectional developmental trends seen in the current data with those that are observed in the longitudinal data gathered from the incoming students whose data are reported in the current study. 


\section{Materials and procedure \\ Convocation survey}

Before each convocation ceremony, participants were approached and asked to fill out a 24-item survey. There were six different versions of the survey, which were distributed at random at each of the convocation ceremonies. The first 23 questions were the same for each survey, and addressed student participation in nine of the domains (arts and culture, health and wellness, diversity and inclusion, global awareness, innovation, university spirit, leadership, community engagement, and career preparation). Overall participation was calculated as the average score on the items that assessed these nine domains. Descriptive statistics for graduating students' participation in these domains are presented in table 1.

The final question on each survey was open-ended and differed for each of the six versions of the questionnaire. While each of these six questions were of interest to the research team, it was established that answering each of them would require too much of the students' time. Instead, the six different versions of the questionnaire were developed, each containing a single open-ended question at the end. Only one of these open-ended questions — the one related to significant learning experiences—was examined in this research.

Arts and culture, health and wellness, diversity and inclusion, global awareness, innovation

Participation was assessed using a single item for each of these five domains (e.g., While at Brock University, how many times did you participate in an event or activity that was related to diversity and inclusion? By diversity and inclusion, were referring to events and activities related to sexuality/sexual relationships, race/culture, social justice, accessibility for people with disabilities etc.). In all cases, participation was assessed on a 6-point scale, with anchors (i.e., the descriptors for the high and low ends of the scale) that were appropriate to the domain in question (see Appendix).

\section{University spirit}

Participation in this domain of the co-curriculum was assessed by taking the average of four questions (involvement in clubs and intramural sports teams; attendance at spirit and varsity sports events). Again, participation for these four questions was assessed on a 6-point scale, with anchors that were appropriate to the domain in question (see Appendix).

\section{Leadership}

Leadership was assessed by asking students whether they had assumed a leadership role for any university event or activity (a yes/no response; see Appendix).

\section{Community engagement}

This domain was assessed by asking students to report separately on the amount of on- and offcampus volunteering they did while attending the university. Both questions measured volunteer hours on a 7-point scale ("0 hours per term, on average" to "more than 50 hours per term, on average"; see Appendix), and an overall community engagement score was created by taking the average of both questions. 


\section{Career preparation}

Students were asked how prepared they felt to look for work or further education. These questions were answered using a 4-point scale (very prepared to not prepared) in both instances (see Appendix).

\section{Significant learning experiences}

Students were asked to describe, in an open-ended manner, one of the most significant learning experiences they had at university, and to indicate the context in which they had that experience (e.g., something they did as part of a course, paying job, volunteer experience, or co-curricular activity; see Appendix).

\section{Mid-degree survey}

Students participating in the mid-degree survey completed the same questions included in the convocation survey, with the exception of those related to important co-curricular experiences and career preparation. Descriptive statistics for the mid-degree students' participation are presented in table 1 .

Table 1: Mean campus-wide co-curriculum participation rates for mid-degree and convocation samples

\begin{tabular}{|l|c|c|}
\hline DOMAIN & MID-DEGREE MEAN (SD) & CONVOCATION MEAN (SD) \\
\hline Arts and culture & $.96(1.32)$ & $1.01(1.19)$ \\
\hline Health and wellness & $.84(.90)$ & $1.05(1.18)$ \\
\hline Diversity and inclusion & $.50(.86)$ & $.69(1.08)$ \\
\hline Global awareness & $.38(.84)$ & $.56(.94)$ \\
\hline Innovation & $.39(.93)$ & $.56(1.04)$ \\
\hline University spirit & $1.05(.80)$ & $.92(.81)$ \\
\hline Community engagement & $1.29(1.25)$ & $1.47(1.41)$ \\
\hline Preparation for job search & N/A & $2.00(.91)$ \\
\hline Preparation for further education & N/A & $1.98(1.02)$ \\
\hline
\end{tabular}

Note: Possible scores were $0-5$ for arts and culture, health and wellness, diversity and inclusion, global awareness, innovation and university spirit. Possible scores for community engagement were $0-6$. Possible scores for job and education preparation were 0-3.

\section{Orientation survey}

The orientation survey contained all of the same questions that were included in the mid-degree survey. However, the wording of the questions and possible responses were altered to reflect the fact that these students were reporting on their intention to participate in co-curricular activities rather than their actual involvement (e.g., How likely are you to participate in events or activities that are related to diversity and inclusion? By diversity and inclusion, were referring to events and activities related to sexuality/sexual relationships, race/culture, social justice, accessibility for people with disabilities etc.). For each of these questions, the 5-point response scale ranged from "definitely will not be" to "definitely will be"; the midpoint of the scale was used to indicate "not sure." 


\section{RESULTS}

\section{Importance of co-curricular experiences}

Only the graduating students at convocation were asked about their most important learning experience while at university. Because the six different versions of the convocation survey were handed out randomly, 170 students received the one in which the open-ended question related to their most important learning experience. Of those, 90 participants (53 percent) answered this open-ended question. In keeping with extant literature (e.g., Bass, 2012) and our hypothesis, student responses demonstrated that they found co-curricular experiences to be important. Indeed, in response to the question concerning their most significant learning experiences, more than half of the participants (60 percent) reported a co-curricular experience rather than an experience from the formal curriculum. In terms of the specific types of co-curricular experiences that were perceived as valuable, students reported on work that they had done for pay (21 percent), volunteering (15 percent), co-curricular activities (10 percent), or engaging in a type of co-curricular activity not specified by the questionnaire (14 percent). Examples included participating in clubs, working on-campus student jobs, and volunteering through programs such as special needs programming for children, or co-curricular trips abroad (during which students volunteer with local or international not-for-profit agencies).

The remaining 40 percent of participants reported an important learning experience for which they received course credit. It is worth noting, however, the majority of these participants (59 percent) described an experience that could be considered high-impact, according to the definitions provided by Kuh (2009). For example, students wrote about course-based service-learning opportunities, clinical and classroom placements, co-op programs, internships, and studying abroad for credit.

\section{Feelings of preparedness for employment or postgraduate studies}

Feelings of preparedness to search for work or apply for postgraduate studies were only examined among graduating students in the convocation sample. Correlational analyses indicated that overall participation in the co-curriculum domains was not significantly associated with feelings of preparedness among students applying for a job $(\mathrm{n}=293 ; r=.05 ; \mathrm{p}=.42)$ or those applying for postgraduate study $(\mathrm{n}=98 ; r=-.03 ; p=.81)$.

\section{Intentions versus actual co-curricular participation}

To examine intentions among incoming students, we contrasted the percentage of students who believed it was likely that they would participate in co-curriculum activities (i.e., those who indicated that they "probably" or "definitely" would get involved) with those who suggested that participation was unlikely (i.e., those who indicated that they "probably" or "definitely" would not get involved). Those who indicated that they were "not sure" are not included in these analyses.

To examine actual participation among mid-degree and graduating students, we began by looking at differences between these two cohorts with respect to their participation in the domains. We used a multivariate analysis to examine this issue, given that self-reports of domain-related participation were often correlated. This finding was unsurprising, given that many students get involved in a variety of co-curricular activities while at university. Across all domains, there was very little evidence of differences in co-curricular involvement between mid-degree and graduating students. As such, we 
elected to combine the findings from these two groups to create a sample we refer to as upper-year students and we report on their results collectively.

\section{Arts and culture}

Among incoming students, 45 percent indicated that they would attend events that were related to arts and culture, while 25 percent suggested that they would be unlikely to do so. In contrast, 56 percent of upper year students reported that they had attended an event related to arts and culture (10 percent reported having been to more than 4 events); 44 percent of this sample indicated that they had never attended an arts and culture event during their time at university.

\section{Health and wellness}

Almost half of incoming students (46 percent) noted that they would likely participate in events or activities related to health and wellness; only a small minority (16 percent) suggested that they would not. In terms of actual participation, 61 percent of upper-year students indicated they had attended a health and wellness event ( 8 percent had been to more than 4 events) and 39 percent indicated that they had never participated in such an event.

\section{Diversity and inclusion}

The number of incoming students suggesting that they would likely participate in events related to diversity and inclusion (26 percent) was similar to those indicating that they were unlikely to do so (31 percent). In terms of the upper-year sample, 40 percent indicated that they had participated in activities related to diversity and inclusion ( 5 percent had participated in more than 4 such events); 60 percent of this group reported that they had never participated in events from this domain.

\section{Global awareness}

Among incoming students, 30 percent suggested they would be likely to participate in activities that promoted global awareness and 26 percent believed that they probably would not. With regard to actual participation, 35 percent of the upper-year students reported having attended events related to global awareness (4 percent had attended more than 4) and 65 percent had never attended an event or activity of this type.

\section{Innovation}

Approximately one third of the sample of incoming students (35 percent) believed that they would get involved in activities related to innovation; a smaller number ( 20 percent) felt that this was unlikely. Among the upper-year students, 30 percent indicated that they had attended at least one innovation-related event and 70 percent reported that they had never participated in this domain.

\section{University spirit}

A large proportion of the incoming students thought it likely that they would participate in the university's spirit events ( 98 percent) and campus clubs (66 percent). Approximately half ( 54 percent) suggested they would get involved in intramural sports. Among upper-year students, 73 percent of students had participated in at least one university spirit event, 45 percent had been members of a campus club, and 38 percent had participated in intramural sports. 


\section{Leadership}

Among the incoming students, 43 percent indicated they were likely to take on leadership positions; however, only 31 percent of upper-year students reported that they had actually assumed a leadership role at least once since beginning their degree.

\section{Community engagement}

Among incoming students, a clear majority (64 percent) of the sample suggested that they would volunteer during the course of their degree; only 8 percent indicated that they would not. In terms of the upper-year sample, 77 percent of the students surveyed indicated that they had done some volunteering, either on- or off-campus; 23 percent reported that they had done no volunteer work.

\section{DISCUSSION}

Our findings provide some insight into postsecondary students' beliefs and behaviours regarding co-curricular involvement and its importance in the context of their degree. Specifically, graduating students asked to report on one of their most significant learning experiences were more likely to mention something that was related to their co-curricular involvement rather than in-class activities. Having said this, co-curricular involvement did not predict graduating students' feelings of preparedness to apply for jobs or further educational opportunities. In terms of actual co-curricular involvement, we observed that students were far more likely to participate in some domains of the co-curriculum than others, and that student intentions to participate in the co-curriculum at the beginning of their degree were not always realized. Each of these findings is discussed in turn.

\section{Importance of co-curricular experiences and feelings of preparedness}

Our data confirm other discipline-specific findings (Lackner \& Martini, 2017) that students find co-curricular experiences to be among the most important learning experiences that they have during the course of their degree. This pattern of results provides some preliminary empirical support for Bass's (2012) assertion that the current cohort of postsecondary students finds greater value in co-curricular experiences than those that are connected to their classes. Why might this be the case? It is possible that students find it easier to see the relevance of co-curricular activities to the "real world" in which they will have to live and work, and consequently believe that such experiences are more meaningful. Indeed, past research has suggested that students evaluate course-based assignments as being only moderately relevant, and this finding may reflect the fact that they often do not spontaneously recognize how those assignments foster skills that are transferable to their personal and professional lives (Martini, Rail, \& Norton, 2015).

Given the important learning that students seem to feel occurs during co-curricular involvement, it is interesting that overall participation was not a significant predictor of graduating students' feelings of preparedness to apply for work or further studies. There are at least four possible explanations for this finding. The first is that while students may feel that co-curricular experiences provide valuable learning opportunities, they might also believe that their classroom-based, disciplinary learning and experience is much more important in terms of determining the success of their future job- or education-related plans. 
In other words, they may feel that future employment will or should arise directly out of their programs of study.

A second explanation suggests that some students may perceive the purpose of higher education to be learning rather than job focused. In a 2017 study conducted by the Times Higher Education of over 60,000 international students from across 65 universities, 58.4 percent stated that the reason they went to university was that they were "passionate about the subject" whereas 38.3 percent stated, "to help me get a job or find a better job” (QS Enrolment Solutions, 2017, p. 6).

A third explanation relates to the idea that even if they do see real value of their co-curricular experiences, it may be that students find it difficult to see how they can leverage those opportunities (and the learning that arises from them) during a job interview or on an application form for postgraduate studies. They may not have the language needed to appropriately articulate the skills gained or the transferability of those skills to the discipline.

Finally, a fourth possibility is that our composite measure (which included participation across all domains) was not a sensitive enough measure of co-curricular involvement in this context. Specifically, there may be only a small subset of co-curricular activities perceived to be relevant to students' future career or education plans, and that subset may well depend on the students' specific next steps. For example, a student who is interested in starting her own software business may feel that participation in some domains (e.g., innovation, leadership, global awareness) will be very relevant (and therefore strongly correlated) with her feelings of preparedness, while she might view other domains (e.g., arts and culture) as less relevant to those particular future plans. By combining involvement in all domains into a single index of participation, it is possible that we failed to capture a more nuanced relationship that might exist between co-curricular engagement and feelings of preparedness for future work or further study. Future research could examine this possibility by asking students to clarify their specific future plans and establishing whether there are predictable relationships between participation in specific domains and the plans described by students. For example, students could be asked whether they believed that activities from specific domains will be of some help in terms of career preparation. This approach might be further enhanced by supplying additional examples of career preparation on the survey (e.g., feeling able to effectively answer questions in a job interview and showcase their skills on a resume or during an interview).

\section{Intentions versus actual co-curricular participation}

While there are some inherent limitations associated with our sample and methods (single university; cross-sectional data), we believe that our descriptive data concerning intended and actual participation shed some preliminary light on patterns of co-curricular involvement across the degree. Among the incoming students, for example, there was a very strong expectation that they would engage in some types of activities, such as volunteering, university spirit events, and campus-based clubs and intramural sports. However, there was a much higher level of uncertainty among new students about other co-curricular domains. For example, when asked about participation in events related to arts and culture, health and wellness, diversity and inclusion, global awareness, and innovation, between 30 and 45 percent of incoming students indicated that they were "not sure." If such a pattern was to be replicated at other postsecondary institutions, it would suggest that university staff and faculty may need to invest time in establishing whether these numbers reflect an uncertainty about what such events 
might entail, or a lack of clarity about why those events might be beneficial for students (or both). For undergraduates who are clearly juggling multiple responsibilities (e.g., classes and paid employment), it is important that they understand what will transpire when they participate in particular kinds of cocurricular activities, how much time will be involved, and what benefits they might realise by investing their time in this way. Had the incoming and outgoing cohorts come together to discuss their intentions versus their actual experiences, the incoming group may have had a greater sense of the value of the other types of co-curricular experiences and more realistic expectations of the time commitment required. The longitudinal survey conducted at the end of the incoming cohort's degree may reveal a difference between their original intentions and their actual involvement.

We observed no meaningful differences in actual co-curricular involvement between students in the middle of their degree versus those who were at the end. This was somewhat surprising given that graduating students would have had, on average, an additional 1.5 to 2 years to have participated in cocurricular activities. Possibly, this trend reflects the fact that students who are inclined to get involved do so early in the degree and have already invested a significant number of hours (thus hitting a "ceiling" with respect to our measure of involvement) well before graduation. This would certainly have impacted our results if such "involved" students were more likely to complete the questionnaire than were those who were less active in the co-curriculum.

Overall, we observed that the upper-year students in our sample were most likely to participate in campus spirit events, as well as events and activities connected with arts and culture, and health and wellness. A much smaller group of our participants had participated in events related to diversity and inclusion (40 percent), global awareness (35 percent) or innovation (30 percent), and relatively few of them ( 31 percent) indicated that they had taken on a leadership role at some point during their university degree. Given the emphasis currently being placed by employers on finding job candidates who have leadership skills and can function effectively in an increasingly global economy, we considered these participation numbers to be somewhat low. Our results highlight the need to establish whether this pattern stems from the fact that there are relatively few opportunities to get involved in these domains, or whether students choose not to because they cannot see a clear connection between such activities and the goals that they have set for themselves.

\section{LIMITATIONS}

The conclusions that we have drawn in this study must be tempered by its limitations. First and foremost, this study is limited by the fact that its participants come from a single university. For example, it is possible that if other colleges and universities have designed a co-curriculum that is more specifically aligned to job preparation then the correlation between participation and career preparedness might be stronger. The generalizability of our findings remains in question until such time as our results can be replicated with a broader sample from a variety of postsecondary institutions.

Further to this point, student responses on our survey were largely quantitative and consequently we can only speculate about the reasons that underlie the patterns we observed in the data. Future research should include more qualitative data collection procedures as a way of further illuminating how co-curricular participation can impact students' postsecondary experience and their feelings of preparedness for a job search or further education. 
Finally, we acknowledge that our sample for students who were at the mid-point of their degree was small, and that the response rate for this group was low (16 percent). This raises legitimate questions about the reliability of our findings for this group, and indicates that any findings should be interpreted with some caution. However, we would also point out that our response rate is relatively consistent with the findings of other researchers who have examined similar methods of online recruitment (e.g., Kaplowitz, Hadlock, \& Levine, 2004).

We should also note that while this study and the literature reviewed suggests that co-curricular engagement can help students develop career-relevant skills (Bass, 2012; Elias, 2014), it is prudent to recognize the neo-liberal implications of the trend within postsecondary to promote student engagement through co-curricular experiences. Students are continually reminded that out of classroom experiences are needed to build a better $\mathrm{CV}$, and higher education then becomes more focused on preparing students for employment than preparing them to be actively engaged socially concerned citizens (Zepke, 2017). As a result, students may be extrinsically rather than intrinsically motivated to participate in the co-curriculum. Some research (Macfarlane \& Tomlinson, 2017) also critiques the inherent privilege that comes with the ability to participate above and beyond the classroom, as well as the challenges associated with the potential lack of accessibility and other university supports.

\section{CONCLUSIONS}

The limitations of our sample notwithstanding, we believe that the findings of this study provide some preliminary insights into students' beliefs and behaviours with regard to co-curricular involvement among postsecondary students. Specifically, we found evidence to support Bass's (2012) assertion that graduating students believe that much of their important learning is derived from co-curricular involvement; however, the absence of a strong connection between our index of co-curricular involvement and graduating students' feelings of preparedness for next steps (job search or further education) would suggest that further research is needed to determine why such a connection might be weak or absent. Given the growing emphasis in postsecondary institutions on career readiness, it would be important to explore what co-curricular activities, in particular, help student acquire feelings of preparedness. Our results also suggest that there is a need to better understand student perceptions concerning the commitment and benefits associated with co-curricular activity. We believe that additional research will be helpful in terms of clarifying these issues, and will provide a stronger foundation for developing co-curricular opportunities that maximize the benefits realized by students.

Tanya Martini is a full professor at Brock University (CAN). Her research focuses on students' ability to articulate their skill set during interviews, and their ability to recognize how university assignments foster transferable skills that are of interest to employers.

Ryan Verbey-Verutis is a librarian with Maple Leaf Educational Systems in Chongqing, China. He assists students in finding and evaluating materials that will aid in their learning.

Jill Grose is the director of the Centre for Pedagogical Innovation at Brock University (CAN). She works in educational development, supporting institutional initiatives that promote effective teaching and learning. 
Brad Clarke is the director of Student Life and Community Experience at Brock University (CAN). He is interested in increasing students' investment in co-curricular learning experiences and the potential for assessment activities to deepen students' engagement in their university experience.

Amy Elder is the director of the Student Success Centre at Brock University (CAN). Her work involves developing and delivering innovative programs, services and partnerships to help students succeed academically and personally.

\section{REFERENCES}

Astin, A. W. (1984). Student involvement: A developmental theory for higher education. Journal of College Student Personnel, 25(4), 297-308. Retrieved from https://www.middlesex.mass.edu/ace/downloads/astininv.pdf

Bass, R. (2012). Disrupting ourselves: The problem of learning in higher education. Educause Review, 47(2), 2333. Retrieved from https://er.educause.edu/ /media/files/article-downloads/erm1221.pdf

Bonet, G., \& Walters, B. R. (2016). High impact practices: Student engagement and retention. College Student Journal, 50(2), 224-235. Retrieved from https://academicworks.cuny.edu/cgi/viewcontent.cgi?article=1101\&context=kb pubs

Borwein, S. (2014a). The great skills divide: A review of the literature. Toronto, ON: Higher Education Quality Council of Ontario. Retrieved from http://www.heqco.ca/en-ca/Research/ResPub/Pages/The-Great-SkillsDivideBridging-the-Divide.aspx

Borwein, S. (2014b). Bridging the divide, part I: What Canadian job ads said. Toronto: Higher Education Quality Council of Ontario. http://www.heqco.ca/en-ca/Research/ResPub/Pages/The-Great-Skills-DivideBridgingthe-Divide.aspx

Elias, K. L. (2014). Employer perceptions of co-curricular engagement and the co-curricular record in the hiring process (Unpublished doctoral dissertation). University of Toronto. http://hdl.handle.net/1807/67968

Kaplowitz, M. D., Hadlock, T. D., \& Levine, R. (2004). A comparison of web and mail survey response rates. Public Opinion Quarterly, 68(1), 94-101.https://doi.org/10.1093/poq/nfh006

Kuh, G. D. (2009). The national survey of student engagement: Conceptual and empirical foundations. New Directions for Institutional Research, 141, 5-20.https://doi.org/10.1002/ir.283

Kuh, G. D., Cruce, T. M., Shoup, R., Kinzie, J., \& Gonyea, R. M. (2008). Unmasking the effects of student engagement on first-year college grades and persistence. Journal of Higher Education, 79(5), 540-563. https://doi.org/10.1353/jhe.0.0019

Lackner, C. L., \& Martini, T. S. (2017). Helping university students succeed at employment interviews: The role of self-reflection in e-portfolios, Teaching and Learning Inquiry, 5(2), 3-15. http://dx.doi.org/10.20343/teachlearninqu.5.2.2

Martini, T. S., Rail, A., \& Norton, C. (2015). Psychology students' understanding of the skill-based learning fostered through university assignments. Teaching of Psychology, 42(4), 335-338. http://dx.doi.org/10.1177/0098628315603182

Macfarlane, B. \& Tomlinson, M. (2017). Critical and alternative perspectives on student engagement. Higher Education Policy, 30, 1-4.https://doi.org/10.1057/s41307-016-0026-4

Pascarella, E. T., \& Terenzini, P. T. (2005). How college affects students, Vol. 2: A third decade of research. San Francisco, CA: Jossey-Bass.

QS Enrolment Solutions (2017). Global International Student Survey 2017. Retrieved from https://www.internationalstudentsurvey.com/international-student-survey-2017/

Roulin, N., \& Bangerter, A. (2013). Students' use of extra-curricular activities for positional advantage in competitive job markets. Journal of Education and Work, 26(1), 21-47. https://doi.org/10.1080/13639080.2011.623122

Stirling, A. E., \& Kerr, G. A. (2015). Creating and documenting meaningful co-curricular experiences in higher education. Journal of Education and Social Policy, 2(6), 1-7. Retrieved from http://jespnet.com/journalsNol 2 No 6 December 2015/1.pdf 
Thompson, L. J., Clark, G., Walker, M., \& Whyatt, J. D. (2013). 'It's just like an extra string to your bow': Exploring higher education students' perceptions and experiences of extracurricular activity and employability. Active Learning in Higher Education, 14(2), 135-147.https://doi.org/10.1177/1469787413481129

Zepke, N. (2018). Student engagement in neo-liberal times: What is missing? Higher Education Research \& Development, 37(2), 433-446. https://doi.org/10.1080/07294360.2017.1370440

\section{APPENDIX: CONVOCATION SURVEY}

While at Brock University, how many arts/culture events did you attend, in total? By arts/culture events we are referring to theatrical productions, concerts, dance recitals, art exhibits etc.

0

1 to 2

3 to 4

5 to 6

7 to 8

more than 8

While at Brock University, how many times did you participate in a Brock University event or activity that was related to your health and wellness? By health and wellness events, we are referring to the University Health Fair, workshops related to mental or physical health, nutrition, courses related to first aid etc.

0

1 to 2

3 to 4

5 to- 6

7 to 8

more than 8

While at Brock University, how many times did you participate in a Brock University event or activity that was related to diversity and inclusion? By diversity and inclusion, we're referring to events and activities related to sexuality/sexual relationships, race/culture, social justice, accessibility for people with disabilities etc. 0

1 to 2

3 to 4

5 to 6

7 to 8

more than 8

While at Brock University, how many times did you participate in a Brock University event or activity that was related to global awareness? By global awareness, we're referring to events and activities related to cultural awareness, environmental awareness, global politics/economics etc.

0

$1--2$

$3-4$

$5--6$

116 Martini, T., Verbey-Verutis, R., Grose, J., Clarke, B., \& Elder, A. (2019). Canadian undergraduates' reports of co-curricular involvement across the degree. Teaching \& Learning Inquiry, $7(1)$. 
7--8

more than 8

While at Brock University, how many times did you participate in a Brock University event or activity that was related to innovation or entrepreneurship? By innovation and entrepreneurship, we're referring to events and activities related to what innovation is, project management, how to start a business etc.

0

1

2

3

4

more than 4

While at Brock University, how many spirit events did you participate in, in total? By spirit events, we are referring to things like Orientation week events, homecoming, Reading Week events, etc.

0

1 to 4

5 to 8

9 to 12

13 to 16

more than 16

While at Brock University, how many different clubs did you belong to? By clubs, we're referring to things like the Eco Club, Dance Club, French Club, Improv, Young Liberals, department-related clubs etc. If you were involved in the same club for a number of years, you should count it as one.

0

1

2

3

4

more than 4

While at Brock University, how many different non-varsity sports teams (e.g., intramural teams or "club" sports teams such as track and field or ball hockey) did you participate in? If you were involved in the same team for a number of years, you should count it as one.

0

1

2

3

4

more than 4 
While at Brock University, how many varsity sports events did you attend, either at home or away?

0

1

5 to 8

9 to 12

13 to 16

more than 16

Did you assume a leadership role in any of the Brock University events or activities discussed in the previous questions? By leadership role, we're referring to things like organizing a club or being a member of a Brock University club's executive, being captain of a sports team, being a stage manager for an arts event, organizing a fundraiser for a group etc.

Yes

No

During your degree, approximately how many hours PER TERM did you dedicate to volunteering ON CAMPUS, on average?

I did not do any on--campus volunteering

I dedicated 1--10 hours per term, on average

I dedicated 11--20 hours per term, on average

I dedicated 21--30 hours per term, on average

I dedicated 31--40 hours per term, on average

I dedicated 41--50 hours per term, on average

I dedicated more than 50 hours per term, on average

During your degree, approximately how many hours PER TERM did you dedicate to volunteering in the COMMUNITY OUTSIDE OF Brock University, on average? By the community outside of Brock

University, we are referring to the Brock University region, your home community, or abroad.

I did not do any volunteering in the community outside of Brock University

I dedicated 1--10 hours per term, on average

I dedicated 11--20 hours per term, on average

I dedicated 21--30 hours per term, on average

I dedicated 31--40 hours per term, on average

I dedicated 41--50 hours per term, on average

I dedicated more than 50 hours per term, on average

How prepared are you to look for work (e.g., you have an updated resume; you know where to find job leads/postings; you are ready for an interview etc.)?

Very prepared

Prepared

Somewhat prepared

Not prepared 
How prepared are you to apply for further education (e.g., you know where to look for information about programs; you know the application steps; you feel prepared to write applications; you know what documents you need etc.)?

Very prepared

Prepared

Somewhat prepared

Not prepared

Please tell us about one of the most significant learning experiences that you had while you were at Brock University. This might include an experience that you had in your courses, part time or full time jobs, extracurricular activities, community service, or any other experiences that you had while completing your degree.

Was the experience you just described...

something that you did for course credit (includes course-related community volunteer experiences, assignments etc.)

something that happened in a part-time or full-time job for which you were being paid something that happened during a volunteer experience that was unconnected to a course something that related to an extracurricular activity (e.g., clubs, sports teams, non-degree courses) none of the choices above applies to this experience

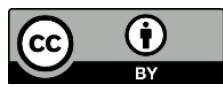

Copyright for the content of articles published in Teaching \& Learning Inquiry resides with the authors, and copyright for the publication layout resides with the journal. These copyright holders have agreed that this article should be available on open access under a Creative Commons Attribution License 4.0 International (https://creativecommons.org/licenses/by/4.0). The only constraint on reproduction and distribution, and the only role for copyright in this domain, should be to give authors control over the integrity of their work and the right to be properly acknowledged and cited, and to cite Teaching \& Learning Inquiry as the original place of publication. Readers are free to share these materials-as long as appropriate credit is given, a link to the license is provided, and any changes are indicated. 